\title{
PENGARUH STRES KERJA, LINGKUNGAN KERJA DAN KOMPENSASI TERHADAP KINERJA KARYAWAN RUMAH SAKIT UMUM KALIWATES (RSUK) JEMBER
}

\section{EFFECT OF WORK STRESS, WORK ENVIRONMENT AND COMPENSATION ON EMPLOYEE PERFORMANCE OF KALIWATES GENERAL HOSPITAL (RSUK) JEMBER}

\author{
Nurul Ihsan, ${ }^{1}$ Anwar, ${ }^{2}$ Akhmad Fahrur Rozi ${ }^{3}$, \\ Fakultas Ekonomi Universitas Muhammadiyah Jember ${ }^{1,2,3}$ \\ Email: Ihsankodok99@ gmail.com ${ }^{1}$, anwar@unmuhjember.ac.id ${ }^{2}$, \\ fahrurrozi@unmuhjember.ac.id ${ }^{3}$
}

\begin{abstract}
ABSTRAK
Penelitian ini dilakukan pada karyawan Rumah Sakit Umum Kaliwates (RSUK) Jember. Penelitian ini bertujuan untuk mengetahui pengaruh stres kerja, lingkungan kerja dan kompensasi terhadap kinerja karyawan Rumah Sakit Umum Kaliwates (RSUK) Jember. Dalam penelitian ini data dikumpulkan dengan alat bantu berupa observasi, wawancara dan kuesioner terhadap 70 responden dengan teknik purpossive sampling, yang bertujuan untuk mengetahui persepsi responden terhadap masing-masing variabel. Analisis yang digunakan meliputi uji instrumen data (uji validitas, dan uji reliabilitas), analisis regresi linear berganda, uji asumsi klasik (uji normalitas, uji multikolinearitas dan uji heteroskedastisitas), dan uji hipotesis (uji t, koefisien determinasi). Dari hasil analisis menggunakan regresi dapat diketahui bahwa variabel stres kerja $(0,589)$, lingkungan kerja $(0,244)$ dan kompensasi $(0,163)$, semuanya berpengaruh positif terhadap kinerja karyawan. Dari uji t diperoleh hasil stres kerja $(0,000)$, lingkungan kerja $(0,000)$ dan kompensasi $(0,003)$, semuanya berpengaruh signifikan terhadap kinerja karyawan.
\end{abstract}

Kata Kunci: stres kerja, lingkungan kerja, kompensasi, kinerja karyawan

\begin{abstract}
ABSTRAK
This research was conducted on employees of Kaliwates General Hospital (RSUK) Jember. This study aims to find out the effect of work stress, work environment and compensation on employees performance of Kaliwates General Hospital (RSUK) Jember. In this research the data collected by using of aids in the form of observation, interview and questionnaire to 70 respondents with purposive sampling technique, which aims to know the perception of respondents to each variables. The analysis used included instrument test data (validity test, reliability test), multiple linear regression analysis, classical assumption test (normality test, multicollinearity test and heteroscedasticity test), and hypothesis test (t-test, coefficient of determination). From the analysis result is using regression can be seen that job stress variable $(0,589)$, work environment $(0,244)$ and compensation $(0,163)$, all of them have positive effect to employees performance. From t-test the result of work stress $(0.000)$, work environment $(0,000)$ and compensation $(0,003)$, all of them have significant effect to employee performance
\end{abstract}

Keywords : work stress, work environment, compensation, employee performance 


\section{PENDAHULUAN}

Sumber daya manusia merupakan salah satu faktor produksi yang mempunyai peranan penting dalam sebuah organisasi untuk mencapai tujuannya Walaupun di dukung oleh sarana dan prasarana serta sumber dana yang berlimpah dari perusahaan, tetapi tanpa dukungan sumber daya manusia yang handal dan baik program perusahaan tidak akan terselesaikan dengan baik. Hal ini menyatakan bahwa sumber daya manusia menunjukkan kunci pokok yang harus sangat di perhatikan dengan segala kebutuhannya. Hal ini di karenakan sumber daya manusia merupakan factor produksi lain yang di miliki oleh organisasi. Stres kerja yaitu tanggapan seseorang terhadap kondisi yang dirasakan baik secara fisik maupun psikologi yang berlebihan karena suatu tuntutan pekerjaan secara internal maupun eksternal. Sehingga konidisi stres ini dapat mengalami ketidakpuasan dalam bekerja dan menurunkan kinerja seseorang. Penelitian yang dilakukan oleh Wartono (2017) menunjukkan bahwa variabel stress kerja berpengaruh signifikan terhadap kinerja karyawan pada karyawan majalah Mother and Baby. Kinerja karyawan juga dipengaruhi oleh kompensasi.

Kompensasi merupakan imbalan yang diberikan oleh perusahaan kepada karyawan atas jasanya dalam melakukan tugas, kewajiban dan tanggung jawab yang dibebankan kepadanya dalam rangka pencapaian tujuan perusahaan. Kompensasi penting bagi karyawan karena besarnya kompensasi mencerminkan ukuran nilai kerja karyawan, yaitu rekan kerja, keluarga dan masyarakat. Penelitian yang dilakukan oleh Ririvega Kasenda (2013) menunjukkan bahwa kompensasi dan motivasi kerja berpengaruh secara bersama terhadap kinerja karyawan PT. Bangun Wenang Beverages Company Manado. Artinya semakin banyak kompensasi yang diberikan akan menambah semangat kerja karyawan. Selain kompensasi kinerja karyawan juga dipengaruhi oleh lingkungan kerja.

Lingkungan kerja merupakan keadaan. Sekitar tempat kerja baik secara fisik yang dapat memberikan kesan menyenangkan, mengamankan, menentramkan dan kesan betah bekerja dan lain sebagainya (Supardi, 2003). lingkungan kerja fisik adalah semua keadaan berbentuk fisik yang terdapat di sekitar tempat kerja yang dapat mempengaruhi karyawan baik secara langsung maupun secara tidak langsung (Menurut Sedarmayanti, 2001). Fery Moulana, dkk (2017) menunjukkan bahwa variabel Lingkungan Kerja secara tidak langsung berpengaruh signifikan terhadap variabel Kinerja Karyawan melalui variabel mediator Motivasi Kerja. Hasil tersebut menjelaskan bahwa lingkungan yang nyaman aman dan bersih akan menambah kesejahteraan karyawan. 
Rumah sakit merupakan sarana kesehatan yang menyelenggarakan pelayanan perorangan meliputi pelayanan promotif, preventif, curative dan rehabilitative yang menyediakan pelayanan rawat inap, rawat jalan dan gawat darurat. Oleh karena itu rumah sakit dituntut untuk memberikan pelayanan yang bermutu sesuai dengan standart yang ditetapkan dan dapat dijangkau seluruh lapisan masyarakat.(Kepmenkes :2008). Rumah Sakit Umum (RSU) Kaliwates jember merupakan salah satu rumah sakit yang ada di Jember dimana dahulu merupakan Balai Kesehatan dan Rumah Bersalin yang didirikan oleh Perusahaan Perkebunan Milik Negara (BUMN) PT Perkebunan XXVI (Persero) Jember.Dalam 3 tahun terakhir ini, Rumah Sakit Umum Kaliwates Jember menunjukkan perkembangan yang cukup baik. Hal ini dapat dilihat dalam tabel kinerja 3 tahun terakhir RSU Kaliwates Jember sebagai berikut :

Tabel 1. Kinerja Pelayanan RSU Kaliwates Jember Tahun 2015-2017

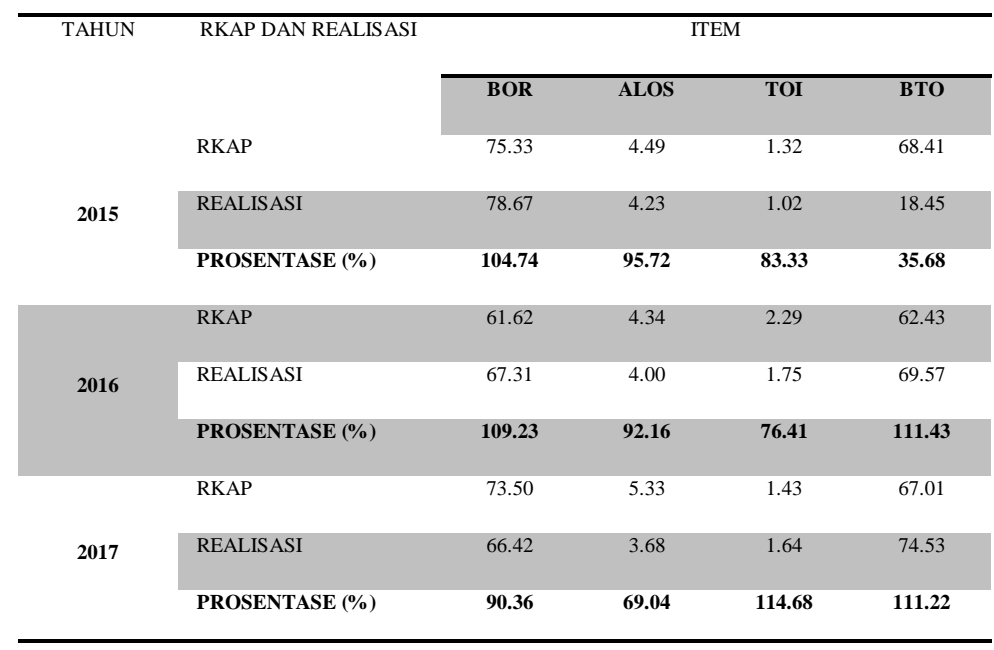

Sumber: RSU Kaliwates Jember

Data di atas menunjukkan bahwa BOR(Bed Occupanty Ratio) yaitu prosentase tempat tidur pada suatu satuan waktu tertentu, masih cukup baik walaupun mengalami kenaikan penurunan angka prosentase. Sedangkan ALOS (Average Length Of Stay) yaitu rata-rata rawatan pasien, menunjukan penurunan pada tiga tahun terakhir ini. Serta TOI (Turn Over Internal) yaitu rata-rata hari, tempat tidur tidak ditempati dari saat terisi ke saat terisi berikutnya dan BTO (Bet Turn Over) yaitu frekuensi tempat tidur, berapa kali dalam satuan waktu tertentu (biasanya 1 tahun) tempat tidur rumah sakit di pakai, masih mengalami fluktuatif atau turun naik selama tiga tahun terakhir ini tapi cenderung positif.

Berdasarkan wawancara terhadap karyawan di rumah sakit, beban kerja perawat/karyawan yang tidak seimbang dapat mengakibatkan stress dan menimbulkan kinerja karyawan menurun. Manajer sulit untuk mengetahui kualitas beban kerja tersebut 
karena lebih mendasarkan pada keluhan-keluhan yang bersifat subyektif. Perencanaan kebutuhan tenaga karyawan yang tidak sesuai dengan kapasitas kerja, sangat berisiko bagi kualitas pelayanan yang diberikan oleh karyawan karena apabila beban kerja tinggi maka ketelitian dan keamanan kerja menjadi menurun. Faktor lain yang dapat mempengaruhi kinerja karyawan adalah mengenai lingkungan kerja. dapat di jelaskan bahwa pada kondisi lingkungan kerja yang buruk, seperti halnya AC pendingin ataupun lainnya yang bermasalah dapat membuat karyawan bersikap malas terhadap pekerjaannya.

Berdasarkan latar belakang di atas maka pokok permasalahan penelitian ini adalah sebagai berikut :

a. Apakah terdapat pengaruh stres kerja terhadap kinerja karyawan Rumah Sakit Umum Kaliwates (RSUK)?

b. Apakah terdapat pengaruh lingkungan kerja terhadap kinerja karyawan Rumah Sakit Umum Kaliwates (RSUK)?

c. Apakah terdapat pengaruh kompensasi terhadap kinerja karyawan Rumah Sakit Umum Kaliwates (RSUK)?

\section{TINJAUAN PUSTAKA}

\section{Stres Kerja}

Stres adalah ketegangan atau tekanan emosional yang dialami seseorang yang sedang menghadapi tuntutan yang sangat besar, Hambatan-Hambatan, dan adanya kesempatan yang sangat penting yang dapat mempengaruhi emosi, pikiran dan kondisi fisik seseorang (Marihot Tua Efendi Hariandja, 2002). Perasaan tertekan yang dialami karyawan dalam menghadapai pekerjaan. Menurut (A.A Anwar Prabu Mangkunegara, 2008) berpendapat bahwa:" penyebab stres kerja, antara lain beban kerja yang dirasakan terlalu berat, waktu kerja yang mendesak, kualitas pengawasan kerja yang rendah, iklim kerja yang tidak sehat, otoritas kerja yang tidak memadai yang berhubungan dengan tanggung jawab, konflik kerja, perbedaan nilai antara karyawan dengan pemimpin yang frustasi dalam kerja”. Kondisi yang muncul dari interaksi antara manusia dan pekerjaan serta dikarakteristikkan oleh perubahan manusia yang memaksa mereka untuk menyimpang dari fungsi normal mereka (Molan, 2006). 


\section{Lingkungan Kerja}

Lingkungan kerja adalah tempat dimana karyawan melakukan aktivitas sehariharinya. Lingkungan kerja dikatakan baik atau sesuai apabila karyawan dapat melaksanakan kegiatan secara optimal, sehat, aman dan nyaman. (Supardi, 2003). Menyatakan lingkungan kerja merupakan keadaan sekitar tempat kerja baik secara fisik yang dapat memberikan kesan menyenangkan, mengamankan, menentramkan dan kesan betah bekerja dan lain sebagainya. Lingkungan kerja memegang peranan penting terhadap baik buruknya kualitas hasil kinerja karyawan. Bila lingkungan kerja nyaman dan komunikasi antar karyawan berjalan lancer, maka dipastikan performa yang dihasilkan pun akan maksimal. Menurut Nitisemito (2006) Lingkungan Kerja adalah segala sesuatu yang ada disekitar para pekerja yang dapat mempengaruhi dirinya dalam menjalankan tugas-tugas yang diembankan oleh perusahaan. Menurut Sedarmayanti (2001) Lingkungan kerja fisik adalah semua keadaan berbentuk fisik yang terdapat di sekitar tempat kerja yang dapat mempengaruhi karyawan baik secara langsung maupun secara tidak langsung.

\section{Kompensasi}

Kompensasi adalah pengaturan keseluruhan pemberian balas jasa bagi employers maupun employee, baik yang langsung berupa uang (finansial) maupun yang tidak langsung berupa uang (nonfinansial). Martoyo (2007) mengatakan bahwa kompensassi adalah imbalan jasa yang di berikan oleh organisasi kepada para tenaga kerja karena tenaga kerja tersebut telah memberikan sumbangan tenaga dan pikiran demi kemajuan organisasi guna mencapai tujuan yang telah ditetapkan (Sastrohadiwiryo, 2005).

Secara umum dalam berbagai kepustakaan dijelaskan terdapat tiga jenis kompensasi, yaitu (1) kompensasi langsung, (2) kompensasi tidak langsung, dan (3) insentif. Kompensasi langsung adalah penghargaan atau ganjaran yang disebut gaji atau upah, yang di bayar secara tetap berdasarkan tenggang waktu yang ditetapkan organisasi. Umumnya, adalah setiap bulan, meskipun ada juga organisasi khususnya sektor swasta memeberikannya dua kali dalam sebulan. Sementara itu, kompensasi tidak langsung adalah pemberian bagian keuntungan manfaat bagi para pekerja diluar gaji atau upah tetap, dapat berupa uang atau barang, sedangkan insentif adalah pengharghaan atau ganjaran yang diberikan untuk memotivasi para pekerja agar produktivitas kerjanya tinggi, dan sifatnya tidak tetap atau sewaktu-waktu. 


\section{Kinerja Karyawan}

Kinerja (prestasi kerja) adalah hasil kerja secara kualitas dan kuantitas yang dicapai oleh seseorang pegawai dalam melaksanakan tugasnya sesuai dengan tanggung jawab yang diberikan kepadanya. Menurut Mangkunegara (2000:67) bahwa kinerja merupakan proses formal untuk melakukan peninjauan ulang dan evaluasi prestasi kerja seseorang secara priodik (Siagian, 2002:248). Penilaian biasanya dilakukab secara berkala dalam interval waktu tertentu (Azhad, dkk. ,2015).

Sehubungan dengan ukuran penilaian prestasi kerja maka kinerja karyawan, menurut Simamora (2004:612), diukur dengan indikator-indikator sebagai berikut :

a. Kuantitas hasil kerja, yaitu yang meliputi jumlah produksi kegiatan yang dihasilkan.

b. Kualitas hasil kerja, yaitu yang meliputi kesesuaian produksi kegiatan dengan acuan ketentuan yang berlaku sebagai standar proses pelaksanaan kegiatan maupun rencana organisasi.

c. Ketepatan waktu penyelesaian pekerjaan, yaitu pemenuhan kesesuaian waktu yang dibutuhkan atau diharapkan dalam pelaksanaan kegiatan.

\section{Hipotesis}

$\mathrm{H}_{1}$ : diduga bahwa terdapat pengaruh antara Stres Kerja terhadap kinerja karyawan pada Rumah Sakit Umum Kaliwates (RSUK).

$\mathrm{H}_{2}$ : diduga bahwa terdapat pengaruh antara Lingkungan Kerja terhadap kinerja karyawan pada Rumah Sakit Umum Kaliwates (RSUK).

$\mathrm{H}_{3}$ : diduga bahwa terdapat pengaruh antara Kompensasi terhadap kinerja karyawan pada Rumah Sakit Umum Kaliwates (RSUK).

\section{METODE PENELITIAN}

Populasi merupakan identitas dari semua objek atau individu yang memiliki karakteristik tertentu, jelas dan lengkap yang akan diteliti. (Hasan, 2002). Objek yang akan diteliti dalam populasi disebut unit analisis atau elemen populasi yang dapat berupa orang, perusahaan, emdia dan sebagainya. Dalam penelitian ini, populasi yang digunakan adalah seluruh karyawan Rumah Sakit Umum Kaliwates (RSUK) yang berjumlah 236 orang. Sampel adalah Sampel merupakan bagian dari populasi yang diambil melalui cara-cara tertentu yang memiliki karakteristik tertentu, jelas dan bisa dianggap mewakili 
populasi. (Hasan, 2002:58). Sampel yang digunakan pada penelitian ini berjumlah 70 orang. Teknik pengambilan sampel yang digunakan adalah menggunakan rumus Slovin.

\section{Analisis Data}

Alat analisis yang digunakan pada penelitian ini adalah regresi linear berganda. Berikut persamaan yang dibuat berdasarkan variabel yang digunakan dalam penelitian ini :

$$
Y=a+b_{1} X_{1}+b_{2} X_{2}+b_{3} X_{3}+e
$$

Analisis data menggunakan uji instrumen data (uji validitas, dan uji reliabilitas), analisis regresi linear berganda, uji asumsi klasik (uji normalitas, uji multikolinearitas dan ujiheteroskedastisitas), dan uji hipotesis (uji t, koefisien determinasi).

\section{HASIL DAN PEMBAHASAN}

\section{Analisis Regresi Linear Berganda}

Analisis regresi digunakan untuk menguji hipotesis tentang pengaruh secara parsial variabel bebas terhadap variabel terikat.

\section{Tabel 2. Hasil Regresi Linear Berganda}

\begin{tabular}{ccc}
\hline No & Variabel & $\begin{array}{c}\text { Koefisien } \\
\text { Regresi }\end{array}$ \\
\hline $\mathbf{1}$ & Konstanta & 0,008 \\
$\mathbf{2}$ & Stres Kerja $\left(\mathrm{X}_{1}\right)$ & 0,589 \\
$\mathbf{3}$ & Lingkungan & 0,244 \\
$\mathbf{4}$ & Kerja $\left(\mathrm{X}_{2}\right)$ & 0,163 \\
\hline
\end{tabular}

Berdasarkan tabel 2 dapat diketahui persamaan regresi yang terbentuk adalah :

$Y=0,008+0,589 X_{1}+0,244 X_{2}+0,163 X_{3}$

Dari persamaan tersebut dapat diartikan bahwa :

a. Konstanta sebesar 0,008 menunjukkan besaran kinerja karyawan 0,008 satuan pada saat Stres kerja, lingkungan kerja dan kompensasi sama dengan nol.

b. meningkatnya Stres kerja per 0,589 satuan akan meningkatkan kinerja karyawan apabila lingkungan kerja dan kompensasi sama dengan nol. Hal ini juga mengindikasikan bahwa stress kerja berpengaruh positif terhadap kinerja karyawan yang berarti semakin meningkat tanggapan karyawan tentang stress kerjaakan 
berdampak pada semakin meningkatnya kinerja karyawan dengan asumsi lingkungan kerja dan kompensasi konstan.

c. Meningkatnya Lingkungan kerja per 0,244 satuan akan meningkatkan kinerja karyawan apabila stres kerja dan kompensasi sama dengan nol. Hal ini juga mengindikasikan bahwa lingkungan kerja berpengaruh positif terhadap kinerja karyawan yang berarti semakin meningkat tanggapan karyawan tentang lingkungan kerjaakan berdampak pada semakin meningkatnya kinerja karyawan dengan asumsi stres kerja dan kompensasi konstan.

d. meningkatnya kompensasi per 0,163 satuan akan meningkatkan kinerja karyawan apabila stres kerja dan lingkungan kerja sama dengan nol. Hal ini juga mengindikasikan bahwa kompensasi berpengaruh positif terhadap kinerja karyawan yang berarti semakin meningkat tanggapan karyawan tentang kompensasiakan berdampak pada semakin meningkatnya kinerja karyawan dengan asumsi stres kerja dan lingkungan kerja konstan.

\section{Uji Hipotesis}

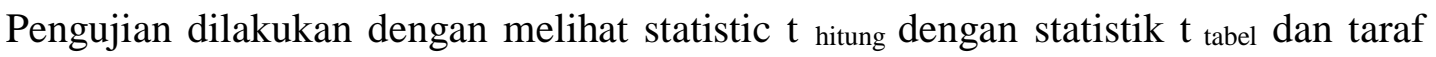
signifikasi ( $p$-value), jika taraf signifikasi yang dihasilkan dari perhitungan dibawah 0,05 maka hipotesis diterima, sebaliknya jika taraf signifikasi hasil hitung lebih besar dari 0,05 maka hipotesisi ditolak.

Tabel 3. Hasil Uji t

\begin{tabular}{|c|c|c|c|c|c|c|}
\hline $\begin{array}{l}\mathrm{N} \\
\mathrm{o}\end{array}$ & Variabel & $\begin{array}{c}\text { Signifik } \\
\text { ansi } \\
\text { Hitung }\end{array}$ & $\begin{array}{c}\text { Taraf } \\
\text { Signifka } \\
\text { nsi }\end{array}$ & $\mathrm{t}_{\text {hitung }}$ & $\begin{array}{c}\mathrm{t} \\
\text { tabel }\end{array}$ & $\begin{array}{c}\text { Keterang } \\
\text { an }\end{array}$ \\
\hline 1 & Stres kerja $\left(\mathrm{X}_{1}\right)$ & 0,000 & 0,05 & $\begin{array}{c}16, \\
15 \\
4\end{array}$ & $\begin{array}{l}1,6 \\
683\end{array}$ & $\begin{array}{c}\text { Signifika } \\
\mathrm{n}\end{array}$ \\
\hline 2 & $\begin{array}{c}\text { Lingkungan } \\
\text { kerja }\left(\mathrm{X}_{2}\right)\end{array}$ & 0,000 & 0,05 & $\begin{array}{l}4,1 \\
83\end{array}$ & $\begin{array}{l}1,6 \\
683\end{array}$ & $\begin{array}{c}\text { Signifika } \\
\mathrm{n}\end{array}$ \\
\hline 3 & Kompensasi $\left(\mathrm{X}_{3}\right)$ & 0,003 & 0,05 & $\begin{array}{l}3,0 \\
59\end{array}$ & $\begin{array}{l}1,6 \\
683\end{array}$ & $\begin{array}{c}\text { Signifika } \\
\mathrm{n}\end{array}$ \\
\hline
\end{tabular}

\section{Uji Koefisien Determinasi $\left(\mathbf{R}^{2}\right)$}

Koefisien determinasi merupakan besaran yang menunjukkan besarnya variasi variabel dependen yang dapat dijelaskan oleh variabel independennya. 


\section{Tabel 4 Hasil Uji Koefisien Determinasi}

\begin{tabular}{ccc}
\hline No & Kriteria & Koefisien \\
\hline $\mathbf{1}$ & $R$ & 0,973 \\
$\mathbf{2}$ & $R$ Square & 0,948 \\
$\mathbf{3}$ & Adjusted $R$ Square & 0,945 \\
\hline
\end{tabular}

Dari tabel 4. diketahui hasil perhitungan regresi bahwa koefisien determinasi yang diperoleh sebesar 0,945. Hal ini berarti 94,5\% variasi variabel kinerja karyawan dapat dijelaskan oleh stres kerja, lingkungan kerja dan kompensasi, sedangkan sisanya sebesar 0,055 atau 5,5\% diterangkan oleh variabel lain yang tidak diajukan dalam penelitian ini.

\section{Pembahasan}

Secara nyata berdasarkan hasil penelitian menunjukkan bahwa secara statistik kedua hipotesis yang diajukan terdukung oleh teori sebelumnya. Dari data pada pengujian hipotesis sebelumnya. Berdasarkan hasil pengujian secara statistik, penjelasan dari masing-masing pengaruh variabel dijelaskan sebagai berikut :

a. Hasil pengujian ini membuktikan bahwa stres kerja mempunyai pengaruh terhadap keputusan pembelian. -Dengan taraf signifikasi 0,00 atau lebih kecil dari 0,05 maka variabel stres kerja dipertahankan guna meningkatkan kinerja karyawan. Menurut Marihot Tua Efendi Hariandja (2002), Stres adalah ketegangan atau tekanan emosional yang dialami seseorang yang sedang menghadapi tuntutan yang sangat besar, Hambatan-Hambatan, dan adanya kesempatan yang sangat penting yang dapat mempengaruhi emosi, pikiran dan kondisi fisik seseorang. Kesimpulan di atas menunjukkan adanya kondisi tertentu dalam lingkungan yang merupakan sumber potensial bagi munculnya stres. Bagaimana bentuk stress yang dihayati tergantung dari karakteristik yang unik dari individu yang bersangkutan serta penghayatannya terhadap faktor-faktor dari lingkungan yang potensial memunculkan stres padanya. Walaupun hampir setiap kelompok orang dihadapkan pada jenis atau kondisi stres yang serupa, tetapi hal ini akan menghasilkan reaksi yang berbeda, bahkan dalam menghadapi jenis stres atau kondisi yang sama setiap individu dapat berbeda-beda pola reaksinya. Hasil ini juga mendukung penelitian sebelumnya oleh Nur Saina (2013) dan Tri Wartono (2017).

b. Hasil dari penelitian ini adalah variabel stres kerja berpengaruh signifikan terhadap kinerja karyawan. Hasil pengujian ini membuktikan bahwa lingkungan Kerja mempunyai pengaruh terhadap kinerja karyawan.Dengan taraf signifikasi 0,00 atau 
lebih kecil dari 0,05 maka variabel lingkungan kerja dipertahankan guna meningkatkan kinerja karyawan. Menurut Nitisemito (2006) lingkungan kerja adalah segala sesuatu yang ada di sekitar para pekerja yang dapat mempengaruhi dirinya dalam menjalankan tugas-tugas yang diembankan oleh perusahaan. Suatu kondisi lingkungan kerja dikatakan baik atau sesuai apabila manusia yang berada didalamnya dapat melaksanakan kegiatannya secara optimal, sehat, aman dan nyaman, kesesuaian lingkungan kerja apat berdampak dalam waktu yang lama, demikian juga dengan lingkungan kerja yang buruk akan mengakibatkan sulitnya memperoleh system kerja yang efektif dan efisien. Hasil ini juga mendukung penelitian sebelumnya oleh Penelitian Ferry Moulana (2017). Penelitian ini dalam menganalisis data menggunakan analisis regresi linier berganda.Hasil dari penelitian ini adalah variabel Lingkungan kerja secara tidak langsung berpengaruh signifikan terhadap kinerja karyawan.

c. Hasil pengujian ini membuktikan bahwa kompensasi mempunyai pengaruh terhadap kinerja karyawan. Dengan taraf signifikasi 0,003 atau lebih kecil dari 0,05 maka variabel kompensasi dipertahankan guna meningkatkan kinerja karyawan. Menurut Martoyo (2007) Kompensasi adalah pengaturan keseluruhan pemberian balas jasa bagi employers maupun employee, baik yang langsung berupa uang (finansial) maupun yang tidak langsung berupa uang (nonfinansial). Kompensasi karyawan merupakan elemen hubungan kerja yang sering menimbulkan masalah dalam hubungan industrial. Masalah kompensasi, khususnya upah, selalu menjadi perhatian manajemen organisasi, karyawan, dan pemerintah. Manajemen memperhitungkan upah karena merupakan bagian utama dari biaya produksi dan operasi, melukiskan kinerja karyawan yang harus dibayar, dan mempengaruhi kemampuannya untuk merekrut tenaga kerja dengan kualitas tertentu. Hasil ini juga mendukung penelitian sebelumnya oleh Ririvega Kasenda (2013). Dalam penelitian ini dalam menganalisis data menggunakan analisis regresi linier berganda. Hasil dari penelitian ini adalah variabel kompensasi berpengaruh signifikan terhadap kinerja karyawan.signifikan terhadap keputusan pembelian. 


\section{KESIMPULAN DAN SARAN}

\section{Kesimpulan}

Dari pengujian secara statistic yang telah dilakukan, maka dapat ditarik kesimpulan sebagai berikut:

a. Stres kerja berpengaruh terhadap kinerja karyawan dengan koefisien regresi yang bernilai positif $(0,589)$ dan signifikasi hitung sebesar 0,000 dan lebih kecil dari 0,05 dan $\mathrm{t}$ hitung $(16,154)>\mathrm{t}$ tabel $(1,6683)$ yang berarti bahwa hipotesis stres kerja mempunyai pengaruh terhadap kinerja karyawan Rumah Sakit Umum Kaliwates (RSUK) Jember.

b. Lingkungan kerja berpengaruh terhadap kinerja karyawan dengan koefisien regresi yang bernilai positif $(0,244)$ dan signifikasi hitung sebesar 0,000 dan lebih kecil dari 0,05 dan $t$ hitung $(4,183)>t_{\text {tabel }}(1,6683)$ yang berarti bahwa hipotesis lingkungan kerja mempunyai pengaruh terhadap kinerja karyawan Rumah Sakit Umum Kaliwates (RSUK) Jember.

c. Kompensasi berpengaruh terhadap kinerja karyawan dengan koefisien regresi yang bernilai positif $(0,163)$ dan signifikasi hitung sebesar 0,003 dan lebih kecil dari 0,05 dan dan $t_{\text {hitung }}(3,059)>t_{\text {tabel }}(1,6683)$ yang berarti bahwa hipotesis lingkungan kerja mempunyai pengaruh terhadap kinerja karyawan Rumah Sakit Umum Kaliwates (RSUK) Jember.

\section{Saran}

a. Rumah Sakit perlu memperhatikan, serta menjaga stabilitas stres kerja yang disebabkan oleh faktor individu, kelompok dan organisasi melalui kegiatan yang memotivasi seperti kegiatan diluar kantor. yaitu, rekreasi, out bond, waktu relaksasi, senam pagi keterbukaan yang pada akhirnya berimplikasi pada kinerja karyawan yang optimal.

b. Di sarankan pihak manajemen juga dapat memastikan kondisi lingkungan kerja tiaptiap jabatan/posisi apakah sudah dapat mendukung karyawan sehingga tujuan perusahaan dan tujuan karyawan dapat tercapai secara seimbang.

c. Dalam rangka meningkatkan kinerja karyawannya, Rumah Sakit Umum Kaliwates (RSUK) perlu memperhatikan kebutuhan karyawan. Misalnya, kompensasi. Karena karyawan merupakan asset penting dari sebuah perusahaan, tanpa karyawan 
perusahaan tidak akan mengalami kemajua. Oleh Karena itu, mensejahterakan karyawan menjadihal yang paling mendasar. Pemberian motivasi juga harus diperhatikan sedemikian rupa sehingga totalitas dalam bekerja akan semakin bertambah baik.

d. Bagi peneliti selanjutnya diharapkan dapat meneliti dengan variabel-variabel 1;ain diluar variabel yang telah di teliti ini agar memperoleh hasil yang bervariatif agar dapat berpengaruh terhadap kinerja karyawan

\section{DAFTAR PUSTAKA}

Alex S. Nitimiseto,2006. Manajemen Personalia Edisi Revisi.Jakarta : Galia Indonesia

Azhad, M Naely, Anwar, Nurul Qomariah. 2015. Manajemen Sumberdaya Manusia. Jember. Cahaya Ilmu.

Hariandja, Mariot Tua Efendi. 2002. Manajemen Sumber Daya Manusia. Jakarta Pt Gramedia Widia Indonesia (Grasindo). Hal 279.

Hasan, Iqbal. 2002. Metodologi Penelitian dan Aplikasinya. Jakarta : Ghalia.

Henry, Simamora. 2004. Manajemen Sumber Daya Manusia. Edisi ketiga. STIE YKKPN. Yogyakarta.

Kasenda, Ririvega. (Kompensasi, Motivasi Pengaruhnya Terhadap Kinerja Karyawan Pada PT. Bangun Wenang Beverages Company Manado). Jurnal EMBA Vol 1 No 3 Juni 2013, Hal 853-859.

Moulana.Ferry, Bambang Swasto Sunuharyo, Hamidah Nayati Utami. 2017. (Pengaruh Lingkungan Kerja Terhadap Kinerja Karyawan Melalui Variabel Mediator Motivasi Kerja pada Karyawan PT. Telkom Indonesia. Tbk Witel Jatim Selatan). Jurnal Administrasi Bisnis (JAB) Vol. 44 No. 1 Maret 2017.

Nur, Saina. (Konflik, Stres kerja dan Kepuasan kerja Terhadap Kinerja Pegawai Pada Universitas Khairun Ternate). Jurnal EMBA Vol 1 No.3 September 2013,Hal 739-749.

Prabu Mangkunegara, Anwar. 2000. Manajemen Sumber Daya Manusia Perusahaan. Bandung : Remaja Rosdakarya.

Prabu Mangkunegara, Anwar. 2005. Evaluasi Kinerja Sumber Daya Manusia. Cetakan kedua. Bandung : PT Refika Aditama

Sastrohadiwiryo, B.S. 2005. Manajemen Tenaga Kerja Indonesia Pendekatan Administratif dan Operasional. Jakarta : PT Bumi Aksara

Sedarmayanti. 2001. Sumber Daya Manusia dan Produktivitas Kerja. Jakarta : Mandar Maju. 
Sondang P, Siagian. 2002. Kiat Meningkatkan Produktivitas Kerja.Jakarta : PT Rinaka Cipta.

Supardi. 2003. Kinerja Karyawan.Jakarta : Ghalia.

Wartono, Tri. (Pengaruh Stres Kerja Terhadap Kinerja Karyawan pada Karyawan Majalah Mother and Baby).Jurnal Ilmiah Prodi Manajemen Universitas Pamulang Vol. 4, No 2, April 2017). 